\title{
Adaptation to time-compressed speech: Phonological determinants
}

\author{
NÚRIA SEBASTIÁN-GALLÉS \\ Universitat de Barcelona, Barcelona, Spain \\ EMMANUEL DUPOUX \\ Laboratoire de Sciences Cognitives et Psycholinguistique, EHESS-CNRS, Paris, France \\ ALBERT COSTA \\ Universitat de Barcelona, Barcelona, Spain \\ and \\ JACQUES MEHLER \\ Laboratoire de Sciences Cognitives et Psycholinguistique, EHESS-CNRS, Paris, France
}

\begin{abstract}
Perceptual adaptation to time-compressed speech was analyzed in two experiments. Previous research has suggested that this adaptation phenomenon is language specific and takes place at the phonological level. Moreover, it has been proposed that adaptation should only be observed for languages that are rhythmically similar. This assumption was explored by studying adaptation to different time-compressed languages in Spanish speakers. In Experiment 1, the performances of Spanishspeaking subjects who adapted to Spanish, Italian, French, English, and Japanese were compared. In Experiment 2, subjects from the same population were tested with Greek sentences compressed to two different rates. The results showed adaptation for Spanish, Italian, and Greek and no adaptation for English and Japanese, with French being an intermediate case. To account for the data, we propose that variables other than just the rhythmic properties of the languages, such as the vowel system and/or the lexical stress pattern, must be considered. The Greek data also support the view that phonological, rather than lexical, information is a determining factor in adaptation to compressed speech.
\end{abstract}

The acoustic/phonetic characteristics of speech vary as a function of speaker, rate of speech, prosody, and so forth. Yet, when we process our native language, we are hardly ever aware of such variability; indeed, these variations are apparently dealt with automatically and effortlessly by the perceptual system. However, when processing artificially degraded speech or when listening to speakers with foreign accents, it is more difficult to make suitable adjustments. Schwab, Nusbaum, and Pisoni (1985) suggest that several sentences are required to adjust to synthetically generated speech. Anecdotally, listening to speech spoken with a foreign accent can also take some time before it becomes fully intelligible. What are the mechanisms responsible for such slow adjustments? Why are some adjustments easier than others? For instance, for a

This research was supported by grants from the Human Frontier Science Program and the Spanish Ministerio de Educación y Ciencia (Contract PB97-0997) and the Catalan Government (Grup de Recerca Consolidat 5120-UB-05). We thank T. Otake (Dokkyo University), K. Forster, and M. Garrett (both at the University of Arizona) for their help in preparing and recording the Japanese and English materials. A.C. is currently at the Psychology Department, Harvard University. Correspondence concerning this article should be addressed to $\mathrm{N}$. Sebastián-Gallés, Universitat de Barcelona, P. de la Vall d'Hebron 171, 08035 Barcelona, Spain (e-mail: sebastia@psico.psi.ub.es). native speaker of English, English spoken with a Dutch accent seems far easier to understand than English spoken with a Japanese accent. Why?

Several studies have shown that language representations in adults are, to some extent, language specific. Listeners behave as if they process speech sounds through the filter of phonemic categories of their maternal language and have difficulty processing nonnative contrasts (Best, McRoberts, \& Sithole, 1988; Goto, 1971; Mann, 1986; Miyawaki et al., 1975; Pallier, Bosch, \& Sebastián, 1997; Sebastián-Gallés \& Soto-Faraco, 1999; Werker \& Tees, 1984). Similar filters operate at the syllabic and suprasegmental levels of representation (Cutler, Mehler, Norris, \& Seguí, 1983, 1989; Dupoux, Christophe, Sebastián, \& Mehler, 1997; Otake, Hatano, Cutler, \& Mehler, 1993; Pallier, Sebastián, Felguera, Christophe, \& Mehler, 1993). Moreover, lexical access strategies are also language dependent. That is, listeners exploit languagespecific cues to find word boundaries in the continuous signal (Cutler \& Norris, 1988; McQueen, Norris, \& Cutler, 1994; Norris, McQueen, \& Cutler, 1995).

Cutler \& Mehler (1993), following the proposals of Abercrombie (1967) and Pike (1946), have assumed that all of the above differences between languages can be accounted for by positing the existence of a small number of broad classes of languages, defined rhythmically. Spe- 
cifically, three classes of languages have been proposed, each of which triggers the use of dedicated processing mechanisms. Languages such as French, Spanish, Catalan, Italian, and Portuguese would fall into the syllabletimed class; languages such as English and Dutch would fall into the stress-timed class; and languages such as Japanese would fall into the mora-timed class. If such a claim is correct, one expects to find that processing a language that belongs to the same class as the maternal language should be easier than processing more distant languages. If so, one could use the perception of degraded signals across languages to explore in more detail the language class hypothesis and, more generally, the influence of rhythm/phonology on processing.

Adaptation to time-compressed speech is a useful method by which to address these issues. In these experiments, participants listen to compressed sentences and try to understand what is being said. A previous study (Mehler et al., 1993) showed that, in the context of high presentation rates, Spanish, Catalan, French, and English subjects adapt their perceptual system and increase their recall performance after listening to a few sentences. In this study, French and English monolingual subjects were presented with sentences compressed at different rates (uncompressed, $50 \%$, and $40 \%$ of their original length) and then were tested on sentences compressed to $40 \%$. Savings were observed for the groups with $50 \%$ and $40 \%$ compressed sentences, but not for the group with the uncompressed ones, as compared with the performance of a group of subjects who had not been previously exposed to any kind of adaptation materials. Analogous results were obtained for Spanish-Catalan bilinguals. Interestingly, these subjects also benefited from being exposed to compressed materials in their second language (monolingual Spanish subjects also benefited from being exposed to compressed Catalan, a language that they did not understand). These results were in contrast to the lack of transfer observed with both monolingual and bilingual French and English subjects, when they were exposed to compressed English or compressed French, before being tested in their maternal languages. Although there were some problems with this study (the experimental procedures used were not the same in all of the different experimental conditions, thus making it difficult to compare the performance of the different groups of subjects being tested), the original results have been confirmed in other studies.

Dupoux and Green (1997) expanded the above observation and found that as few as 5-10 sentences are sufficient for adaptation to take place. Moreover, they noticed that neither a change of speaker nor a change in the compression rate significantly affects adaptation. Dupoux and Green argued that these effects show that adaptation takes place at a relatively abstract level. In a study by Altmann and Young (1993), English speakers tested with compressed materials made from nonsense words showed savings from exposure to these compressed materials; therefore, it seems that lexical access and/or com- prehension does not seem necessary for adaptation to occur. Pallier, Sebastián-Gallés, Dupoux, Christophe, and Mehler (1998) also replicated and extended some of the previous findings of Mehler et al. (1993). Interestingly, they observed benefits when monolingual British subjects were exposed to highly compressed Dutch before being tested with English sentences.

So far, all of these experiments have shown that subjects can adapt to fast speech even with signals that do not belong to their mother tongue. Could it be that adaptation to compressed speech is a general phenomenon that applies for all speeded signals, irrespective of rhythm/ phonology?

Two studies suggest that this is not the case. Aside from the original study of Mehler et al. (1993), Pallier et al. (1998) also found a case in which compressed speech in one language failed to trigger adaptation in another language-namely, French and English showed no crossadaptation. These results suggest that, first, adaptation to speeded signals is not a general phenomenon but, rather, depends on the linguistic properties of the adapting signal and second, that the relevant properties are rhythmical/ phonological: English and Dutch are in the same rhythmic class, as are Catalan and Spanish, and both show adaptation. English and French are not in the same rhythmic class and show no adaptation. However, alternative accounts are conceivable, and the English-French study has several limitations.

First, even though comparable compression rates were used for English and French in the Pallier et al. (1998) study, English globally yielded very poor performance, as compared with French. This effect could have resulted from the fact that English is intrinsically less compressible than French or, more plausibly, from some initial differences in the uncompressed French and English materials. In any event, this difference in base performance raises the possibility that the compressed English materials may have been too degraded to function as adaptation material. It is, then, important to replicate this finding with adaptation materials that are still perceptible.

Second, the absence of English-French cross-adaptation could be related to the fact that, in this particular experiment, the subjects were bilinguals. Bilinguals may use one processing strategy for one language and apply itinadequately - to the other. This would yield a cost that could potentially cancel out any purely phonological benefit from the adapting sentences. Such a processing cost would not arise in monolinguals, who would not even attempt to process the foreign language beyond the phonological level. True enough, Pallier et al. (1998) tested Catalan-Spanish bilinguals and found, in this population, cross-adaptation between Catalan and Spanish stimuli. But French and English have less overlap in morphology and lexical roots than do Catalan and Spanish, and this difference might play a role in bilingual processing (more on this problem below). Moreover, all of the published monolingual studies have found an adaptation effect across languages. Thus, it is important to replicate differences 
in adaptability across languages that the subjects do not understand.

Finally, even if the problems raised above are properly addressed, it still is the case that some factors other than phonology could be responsible for the observed pattern of results. Indeed, it turns out that, in all the cases in which cross-adaptation was observed (Catalan-Spanish and English-Dutch), the two languages not only had similar phonologies and rhythm, but also were closely related historically. As a consequence, they had very similar lexicons, morphological systems, and syntax. In contrast, the case in which, putatively, no cross-adaptation obtained (i.e., French-English) involved two languages that not only had different phonologies, but also were historically more distant. In other words, phonological and lexical distances were confounded. French, Spanish, and Catalan are Romance languages; most of their lexical roots derive from Latin. English, in contrast, is a Germanic language. It is true that English incorporates many words with a Latin origin, but they are less frequently used than their Germanic counterparts (Finegan, 1987). Could it be that adaptation to compressed speech is linked to these lexical factors, rather than to phonological/rhythmical ones? The present study addresses this question.

The research reported here extends the results of the experiments of Pallier et al. (1998) and helps us to rule out some conceivable explanations for the results observed. In the present research, understanding of compressed Spanish under different pretest conditions was compared. In each condition, subjects were exposed to different time-compressed languages. Each of these languages differs from Spanish in a systematic fashion. In the first experiment, the languages to which the subjects were exposed were Spanish, Italian, French, English, and Japanese. None of the last four languages was spoken by the subjects. Italian and French are phonologically (and lexically) close to Spanish, whereas Japanese and English are more distant. In order to avoid degrading the stimuli too much with very high compression rates, we adjusted the compression rates for each language, so that subjects were still able to perceive the individual segments. In Experiment 2, we used a language that shares rhythmic and phonological properties with Spanish but overlaps minimally in terms of lexical roots-namely, Greek. This helped us to tease apart the lexical from the phonological factors in adaptation to time-compressed speech.

\section{EXPERIMENT 1}

\section{Method}

Subjects. One hundred twenty native Spanish subjects participated in this experiment. They were all undergraduate psychology students at the University of Barcelona, and they received extra course credit for their participation. The subjects were randomly assigned to one of six experimental groups. Five groups received one of the five different adaptation languages (Spanish, Italian, French, English, and Japanese groups), whereas the sixth group did not receive any adaptation sentence (control group). There were 20 subjects in each group. None of the subjects had any hearing loss. They filled out a questionnaire on their knowledge of foreign languages. Most of them had studied English as their main foreign language at school (from the age of 12 until they went to the university, at approximately 18 years of age; in the Spanish schooling system, two foreign languages are taught, the second foreign language being taught only for 3 years before going to the university). The subjects tested in the adaptation to compressed English were among the volunteers who had declared that they had studied French as their main foreign language at school. They rated themselves as having a very low level of comprehension of spoken English ( 0 or 1 on a 5-point scale). Also, most of the subjects had studied French as a second foreign language at school. The subjects in the French group were selected from the volunteers who had not studied French as their main foreign language and who reported having difficulty understanding spoken French (they rated themselves as having a very low level of understanding for spoken French, 0 or 1 on a 5-point scale). Around half of the subjects reported having had occasional contact with Italian (e.g., having spent a vacation in Italy with their school), but none of them reported having studied or having had an extensive exposure to Italian. The subjects claimed to have had no previous exposure to Japanese (except for the occasional sentences heard in movies or on television).

Materials. Ten sentences in each language (Spanish, Italian, French, English, and Japanese) were selected as the adaptation utterances. According to the data of Dupoux and Green (1997), this is the number of adaptation sentences that is likely to guarantee that benefits will have reached asymptote. All the sentences were 12-31 syllables long and were recorded by a female native speaker of each one of the languages (English was recorded by an American speaker). The sentences were all in a declarative mode, with a wide variety of syntactic structures, and the speakers received instructions to pronounce them in a normal, clear way. Table 1 shows the number of syllables, duration values, and articulation rates for the 10 sentences used in each adaptation phase. These sentences were digitized at $16 \mathrm{kHz}$ and compressed by using the PSOLA algorithm (Charpen-

Table 1

Average and Standard Deviations of the Number of Syllables, Duration Values, and Articulation Rates for the 10 Induction Sentences for Each Language and the 5 Experimental Test Sentences

\begin{tabular}{|c|c|c|c|c|c|c|}
\hline \multirow[b]{2}{*}{ Language } & \multicolumn{2}{|c|}{ Number of Syllables } & \multicolumn{2}{|c|}{ Duration (in Seconds) } & \multicolumn{2}{|c|}{$\begin{array}{l}\text { Articulation Rate } \\
\text { (Syllables/Seconds) }\end{array}$} \\
\hline & Average & $S D$ & Average & $S D$ & Average & $S D$ \\
\hline Spanish & 15.9 & 4.7 & 2.84 & 0.71 & 5.59 & 0.68 \\
\hline Italian & 16.7 & 2.0 & 2.81 & 0.22 & 5.94 & 0.22 \\
\hline French & 15.5 & 2.7 & 2.58 & 0.27 & 6.01 & 0.72 \\
\hline English & 14.8 & 0.8 & 2.42 & 0.15 & 6.12 & 0.34 \\
\hline Japanese & 27.7 & 2.0 & 4.43 & 0.40 & 6.24 & 0.53 \\
\hline Greek & 15.2 & 3.3 & 2.35 & 0.64 & 6.47 & 0.73 \\
\hline Spanish, test & 16 & 4.3 & 2.80 & 0.84 & 5.76 & 0.49 \\
\hline
\end{tabular}


tier \& Stella, 1986). This algorithm is fully automatic and general and can be applied to any sounds, speech or nonspeech. Briefly, the algorithm automatically segments the signal into successive overlapping chunks that are synchronized to pitch periods when the signal is periodic and are distributed regularly when it is not. Then, neighboring chunks are superimposed and averaged to create a single chunk. The number of chunks that get averaged into one depends on the compression rate. For instance, for a compression rate of $50 \%$, every other chunk is superimposed and averaged with the following one. This compression algorithm is fairly commonly used in many commercial and freeware sound editor packages.

The compression rates for each adaptation language were the following: Spanish, 38\%; Italian, 30\%; French, 37\%; English, 50\%; and Japanese, $50 \%$. Percentages refer to the length of compressed sentences relative to the uncompressed ones. Thus, for instance, compressed French sentences lasted $37 \%$ of the original duration. For the nonnative languages, these percentages were established after a pilot study in which the maximal speech rate at which subjects were still able to pick up some syllables was determined. In this pilot study, another group of native Spanish subjects was presented with the same compressed sentences as those that were to be used in the main study. They were asked to write down as much as they could from what they heard (the same instructions and experimental procedure used later; see below). The criterion by which to fix the compression rate was that, in the last five adaptation sentences, the subjects were able to correctly identify between $15 \%$ and $25 \%$ of the original syllables. Between 6 and 16 subjects were tested in this pilot study for each language ( 6 subjects with the Italian sentences, 9 subjects with the French sentences, 9 with the Japanese ones, and 16 with the English sentences). Between one and three different compression rates were tested for each language (one for Italian, two for French and Japanese, and three for English). For the Spanish sentences, the compression rate of $38 \%$ was identical to that used in the Pallier et al. (1998) study.

Five new Spanish sentences were selected for the experimental phase (see the Appendix). These sentences were compressed to $38 \%$ of their original length. Their length varied between 15 and 21 syllables. All the subjects received the same five experimental sentences in all the conditions. A different female speaker recorded the Spanish experimental and the Spanish adaptation sentences. Thus, all the groups, including the Spanish one, had a change of speaker between the adaptation and the experimental phases.

Procedure. The subjects were individually tested in a soundattenuated booth. They wore headphones (Sennheiser HMD-224) and were instructed to write down as much as they could of each sentence they heard, even when the sentences were in a language that they could not understand. They had to write down the sentences on a sheet of paper with lines numbered from 1 to 15 , and a thick line was drawn between numbers 10 and 11 . The subjects were specifically instructed that the sentences would be presented at a very high speech rate and that, after Sentence 10, the language of the sentences would switch to Spanish. The Spanish adaptation group was told to expect a change of speaker between Sentences 10 and 11 . The control group heard only the five experimental sentences; accordingly, their answer sheets only had numbers 1 to 5 .

The subjects were given as much time as they needed to write down their answers; the experimenter refrained from administering the next sentence until the subjects indicated that they were ready by raising their hands. The whole experimental session did not last more than $15 \mathrm{~min}$.

\section{Results}

The subjects' responses were scored according to the percentage of correct syllables reported on the five experimental sentences (the same for all the subjects). This measure is the same as the one employed in the Pallier et al. (1998) study. There are two main reasons why it was preferable to score in terms of the percentage of correct syllables rather than the percentage of correct words. First, it provided a more fine-grained analysis of subjects' responses, since partially correct responses could be scored differentially from total failures. For instance, in the first test sentence, the word "julio" was often reported as "junio": scoring in terms of correct whole word would have implied that answers like "junio" were incorrect (exactly as if subjects had written nothing), whereas scoring it in terms of number of syllables allowed us to score it with one syllable - the first one--being correct. This is especially important in a language such as Spanish, where most of the words are two and three syllables long (and the number of monosyllabic content words is relatively small; for instance, in the LEXESP database [Sebastián-Gallés, Martí, Cuetos, \& Carreiras, 1996], out of the 14,876 listed nouns, only 144 are monosyllabic). Second, Spanish is a language with a rich inflectional morphology. It was relatively common that the subjects made errors in the precise inflected form being heard (for instance, in the first experimental sentence, many subjects reported "dijo" ["said," third person singular past] instead of "dije" ["said," first person singular past]). Again, scoring in terms of syllables allowed a finer grained analysis of subjects' responses and made it unnecessary to formulate additional decisions, such as having to consider all inflected forms of a word as correct answers or otherwise.

The mean percentages for each group of subjects are shown in Figure 1. A global analysis of variance (ANOVA), with experimental condition (adaptation language) as a between-subjects variable, was performed on the average of correct syllables reported by each subject for the five experimental sentences. The analysis showed a significant effect $[F(5,114)=13.3, p<.0001]$.

A Tukey multiple comparison of means showed that the groups of subjects being adapted to Spanish and Italian differed from the control, French, English, and Japanese groups (both at $p<.0001$ ). No other comparison of means reached significance. To assess whether the reported results arose from differences in the ability of subjects to partially understand the compressed sentences (it should be remembered that most of the subjects had received some training in one of the languages during their secondary schooling), the mean number of correctly reported content words in the adaptation sentences was calculated for the Italian, French, English, and Spanish groups. This measure, which was intended to assess possible differences in the degree of understanding of the adaptation sentences, was not estimated for the Japanese group, since these subjects had no previous knowledge of this language and, thus, were unable to understand any word. Homophones or rough phonetic transcriptions of the original words were accepted as correct words. The mean percentages of content words correctly reported in the adaptation sentences were $85.2 \%(S D=3.7)$ for the Spanish ones, $11.0 \%(S D=7.7)$ for the Italian ones, 


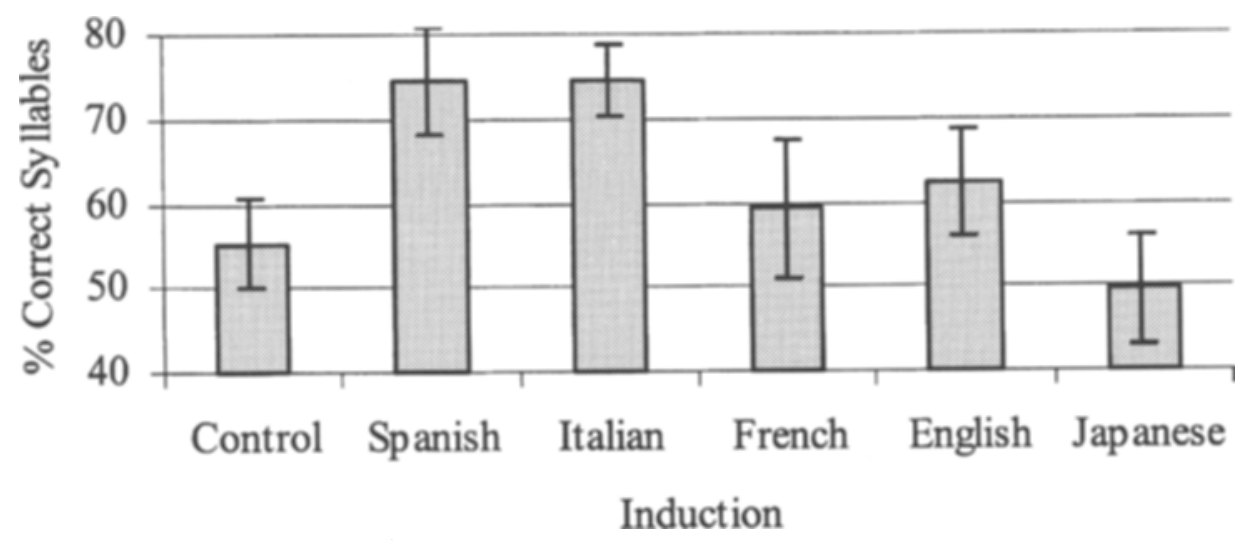

Figure 1. Mean percentages and standard deviations of correct syllables for the experimental sentences in Experiment 1.

$14.2 \%(S D=18.6)$ for the French ones, and $8.2 \%(S D=$ 7.1) for the English ones. ${ }^{1}$ A Tukey multiple comparison of means showed no differences between the Italian, French, and English groups, and they all differed from the Spanish group $(p<.0001)$.

\section{Discussion}

The results of this experiment basically replicate the findings reported in Pallier et al. (1998). They show that when listening to foreign languages, our speech perception system adjusts to the properties of that language. When the foreign language shares many properties with the speakers' native one, subjects benefit from previous exposure to compressed speech, just as if they had heard their own language. In other words, adaptation to compressed Italian sentences produced a benefit equivalent to adaptation to Spanish, for native Spanish speakers. In contrast, adaptation to languages that are more distant from Spanish, such as English and Japanese, produces no benefit for the perception of compressed Spanish; Japanese produces qualitatively the poorest adaptation, although the difference with the control group was not significant. However, contrary to our expectations, we have not been able to observe any significant transfer from French to Spanish, although both languages have phonological properties that are similar and share many lexical roots. We will come back to this issue in the General Discussion section. Finally, our results suggest that adaptation does not depend on comprehension of the adapting sentences. Indeed, the subjects could comprehend much more of the compressed Spanish than of the compressed Italian adaptation sentences ( $85 \%$ vs. $11 \%$ ); nevertheless, both sets of sentences yielded the same amount of adaptation. Conversely, Italian sentences yielded much more adaptation than French sentences, yet the subjects could comprehend the adaptation sentences to a similar degree (indeed, French was even slightly better: $11 \%$ vs. 14\%).

Before drawing any strong conclusions, however, we have to consider a possible alternative explanation for the reported results. As was pointed out before, the adaptation languages were compressed to different rates, which were determined in a pilot study. We chose rates that would ensure that, across languages, although subjects would be unable to understand the languages, they would still be able to pick up a similar number of syllables. To achieve this, different languages required different compression rates. However, English and Japanese were less compressed than Italian, French, and Spanish, and it turned out that English and Japanese yielded the poorest adaptation. This might simply be accounted for by the fact that adaptation is worst when the adapting sentences are less compressed than the test sentences. To test this hypothesis, we carried out another experiment, using two different compression rates within a single language (Greek): One compression rate was similar to the Spanish-Italian group (30\%), and the other was similar to the English-Japanese group (50\%). If the pattern of results in Experiment 1 is due to differences in the compression rates of the adaptation and the test sentences, significant differences between the two adaptation rates ought to be observed in Experiment 2. The interest in using Greek as an adaptation language was based on the following. Although we ruled out comprehension of the adaptation sentences as a factor accounting for the adaptation effect, it is still possible that lexical/morphological overlap between languages plays a role. Hence, even if, as we have shown, the subjects could not comprehend much of the compressed Italian sentences, it still is possible that their mental lexicons were activated by the lexical roots of Italian, which are much closer to the roots of Spanish than they are to those of English or Japanese. So, this second experiment had two goals: first, to study to what extent the different compression rates of the adapting sentences can affect the performance in the experimental sentences and second, to verify whether the results are due to any kind of lexical overlap between Spanish and the adapting languages.

\section{EXPERIMENT 2}

Greek is a language that has the same rhythmic characteristics of Spanish, but it is not a Romance language and 
has a relatively limited lexical overlap with Spanish (see Table 2). Greek is syllable timed (Dauer, 1983), with a syllabic structure and an accent pattern that are similar to Spanish. If the differences observed in Experiment 1 are due to the rhythmic similarity of the adapting and test sentences, the subjects should behave alike, regardless of whether they were adapted to compressed Greek, compressed Spanish, or compressed Italian. Alternatively, if the results are due to lexical similarities between the Romance languages (in terms of both content words and functional words), compressed Greek should not help the subjects as much as Italian and French, languages that have many lexical roots and functional words that are similar in Spanish. Indeed, its results should be similar to those for Japanese or English. As was mentioned above, two different compression rates were used to test whether the results of Experiment 1 were due to differences in compression rates. One of the groups listened to Greek sentences compressed to $30 \%$ of their original length, whereas the other group listened to Greek sentences compressed to $50 \%$ of their initial duration.

\section{Method}

Forty new subjects from the same population as that in Experiment I were tested in this experiment. As in the previous experiment, the subjects' knowledge of foreign languages was assessed. Specifically, they declared having no previous knowledge of Greek (just occasional contact from television or movies).

Ten adaptation sentences in Greek were selected. The sentences were compressed, using the same algorithm as that described in Experiment 1 . Twenty subjects listened to Greek sentences compressed to $30 \%$ of their initial duration, and 20 subjects listened to Greek sentences compressed to $50 \%$ of their initial duration. These two groups are henceforth referred to as Greek30 and Greek50. The experimental procedure was the same as the one used in Experiment 1.

\section{Results and Discussion}

Mean percentages for each group of subjects in the two new experimental conditions (against the control and Spanish groups) are shown in Figure 2. A pooled ANOVA of the data of the Greek 30 and Greek50 groups was performed, pooled together with those of Experiment 1 for the control and Spanish groups. In this analysis, the experimental condition (adaptation language) had four values. The analysis was performed on the average number of correct syllables reported by each subject. The analysis showed a significant effect $[F(3,76)=$ $16.4, p<.0001]$.

A Tukey multiple comparison of means between the two Greek groups and the Spanish and control groups showed that the Greek 30 and Greek50 did not differ from each other, or from the Spanish group, whereas both of them differed from the control group $(p<.0001)$.

The lexical overlap of the Greek adaptation sentences with the Spanish lexicon was very small. Indeed, we calculated the number of words that had a similar pronunciation in both languages (we considered there to be an overlap if at least the first two phonemes were shared in both languages). There were only five words that met this condition: Gr: treno, Sp: tren (Engl: train); Gr: Europis, Sp: Europa (Engl: Europe); Gr: turkika, Sp: turco (Engl: Turkish); Gr: taverna, Sp: taberna (Engl: tavern); and Gr: dio, Sp: dos (Engl: two). Incidentally, "taverna" was the last word of one of the sentences, but regardless, no subject reported it. In fact, using the scoring procedure described in Experiment 1, we found that the subjects were totally unable to report any word in the Greek sentences (score, $0 \%$ ).

The results of Experiment 2 show that adaptation to time-compressed Greek has the same effect as adaptation to time-compressed Spanish: both of the groups of subjects adapted to time-compressed Greek (Greek30 and Greek50), like the group adapted to time-compressed Spanish, performed significantly better than the control group. The main goal of this experiment was to test the hypothesis that the pattern of results observed in the previous experiment was due to differences in the time-

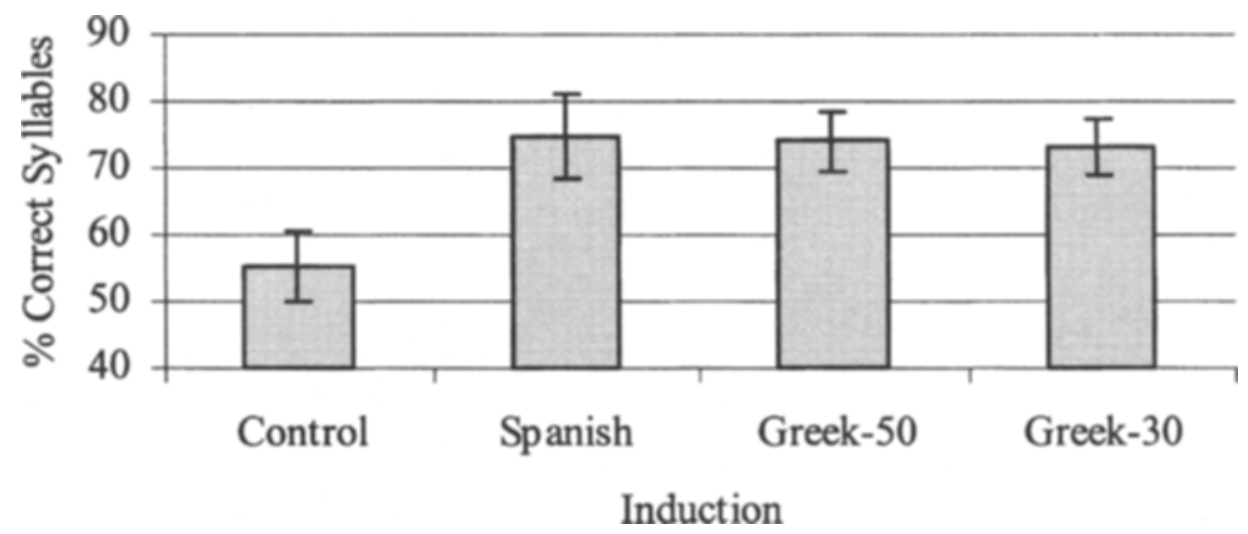

Figure 2. Mean percentages and standard deviations of correct syllables for the experimental sentences in Experiment 2. 
compression rates or to similarities at the lexical level between the adaptation and the test languages. The results of Experiment 2 rule out such explanations.

\section{GENERAL DISCUSSION}

In the two experiments reported above, we have assessed the costs/benefits for Spanish subjects processing compressed Spanish sentences from being exposed to time-compressed sentences from different languages. The observed pattern of results corroborates and expands the results of Pallier et al. (1998). That is, adaptation to compressed speech depends on the linguistic properties of the adapting signal. Some languages function as adapting stimuli, whereas others do not. Moreover, we found that these results depend neither on the subjects' understanding of the adapting signals nor on the exact compression rate used in the adaptation stimulus (at least in the $30 \%-50 \%$ range).

The combined cross-linguistic results of Mehler et al. (1993) and Pallier et al. (1998) already suggest that adaptation does not depend on understanding the adapting speech. Adaptation also occurs with nonwords (Altmann \& Young, 1993) and does not depend on guessing strategies or other task-specific strategies (Dupoux \& Green, 1997). Moreover, in our two experiments, we found no correlation between understanding of the context sentences and adaptation. It seems, then, safe to conclude that adaptation occurs as a relatively low-level process, probably operating sublexically. Yet, Dupoux and Green showed that the effect cannot be a low-level adjustment to very specific kinds of acoustic signals, since adaptation was found to transfer across voices (male vs. female). Similarly, we found that adaptation transfers across different compression rates. All of this is consistent with the view that adaptation operates at a level more abstract than the acoustic/phonetic - presumably, the interface between the phonetic and the phonological representations. There are, then, two questions that need to be addressed. The first one refers to the nature of the mechanism responsible for adaptation, and the second one refers to the nature of the sublexical (phonological) properties of the languages responsible for adaptation (or nonadaptation).

Concerning the nature of the mechanisms, Dupoux and Green (1997) discuss two possibilities: One relates to speaking-rate normalization processes, the other to a longer term perceptual-learning process. Given that the adaptation effects were found to resist a change in speakers and to persist over a set of five uncompressed sentences, Dupoux and Green argued that they were unlikely to be due entirely to speaking-rate normalization processes, which are rather local and speaker specific. The observed effects seem more likely to be due to a relatively long-term adjustment in the sublexical mapping of speech onto phonological representations. One can speculate that such adjustments are comparable with those that occur when one learns to deal with a foreign or a regional accent that systematically alters some aspects of the phonetic-to-phonological mapping. Consistent with this view is our finding that the adaptation is not uniform across languages. Certain languages are more likely than others to yield adaptation, and those are precisely the languages that have phonological overlap with the target language. Indeed, our results allow us to discard lexical overlap as the critical factor promoting adaptation. As Table 2 shows, Romance languages have very similar lexical entries. Similarly, Germanic languages also have analogous word forms. Thus, the previous adaptation results of Pallier et al. (1998) could have come from lexical activation during the presentation of adapting stimuli, rather than from phonology per se. This option now seems unlikely, given the results with Greek and French. Indeed, we found that Greek, a non-Romance language, was as effective as Italian as an adapting language (in fact, both were as effective as Spanish itself). Notice, however, that the underlying lexical roots in Greek and Spanish do not coincide, and hence, it is unlikely that the lexicon plays a role in the adaptation to compressed speech. What parameter, then, can be responsible for the adaptation to compressed speech?

Leaving aside, for the moment, the case of French, our data are congruent with the hypothesis proposed by Cut-

Table 2

Summary Characteristics of the Languages Tested With Speech Compression

\begin{tabular}{|c|c|c|c|c|c|c|c|c|}
\hline Characteristic & Dutch & English & Japanese & French & Spanish & Italian & Catalan & Greek \\
\hline Language family & Germanic & Germanic & Japanese & Romance & Romance & Romance & Romance & Hellenic \\
\hline \multirow[t]{5}{*}{ content words } & hand & hand & te & main & mano & mano & $\mathrm{ma}$ & chjeri \\
\hline & tong & tongue & gengo & langue & lengua & lingua & llengua & glossa \\
\hline & huis & house & & maison & casa & casa & casa & spiti \\
\hline & $\operatorname{man}$ & man & ningen & homme & hombre & uomo & home & andhras \\
\hline & $\begin{array}{l}\text { vliegen } \\
\text { stress }\end{array}$ & $\begin{array}{l}\text { fly } \\
\text { stress }\end{array}$ & $\begin{array}{l}\text { tobu } \\
\text { mora }\end{array}$ & $\begin{array}{l}\text { voler } \\
\text { syllable }\end{array}$ & $\begin{array}{l}\text { volar } \\
\text { syllable }\end{array}$ & $\begin{array}{l}\text { volare } \\
\text { syllable }\end{array}$ & $\begin{array}{l}\text { volar } \\
\text { syllable }\end{array}$ & $\begin{array}{l}\text { petao } \\
\text { syllable }\end{array}$ \\
\hline Number of vowels & 16 & 15 & 5 & 14 & 5 & 7 & 8 & 5 \\
\hline Stress & $\begin{array}{l}\text { variable } \\
\text { stress }\end{array}$ & $\begin{array}{l}\text { variable } \\
\text { stress }\end{array}$ & $\begin{array}{l}\text { variable } \\
\text { stress }\end{array}$ & $\begin{array}{l}\text { fixed stress, } \\
\text { word final }\end{array}$ & $\begin{array}{l}\text { variable } \\
\text { stress }\end{array}$ & $\begin{array}{l}\text { variable } \\
\text { stress }\end{array}$ & $\begin{array}{l}\text { variable } \\
\text { stress }\end{array}$ & $\begin{array}{l}\text { variable } \\
\text { stress }\end{array}$ \\
\hline \multirow{4}{*}{$\begin{array}{l}\text { Adaptation results } \\
\text { (Spanish subjects) } \\
\text { Adaptation results } \\
\text { (English subjects) }\end{array}$} & & & & & & & & \\
\hline & & no & no & no & yes & yes & yes & yes \\
\hline & & & & & & & & \\
\hline & yes & yes & & no & & & & \\
\hline
\end{tabular}


ler and Mehler (1993), who suggested that there are three basic language classes: syllable timed, stress timed, and mora timed. Dutch and English are both stress timed, and they show cross-adaptation; Spanish, Italian, and Greek, three syllable-timed languages, also show crossadaptation. In contrast, in none of the between-classes tests was there any indication of adaptation. Nevertheless, one data point-namely, the fact that French, a syllabletimed language, does not facilitate the perception of compressed Spanish-poses a problem for a purely rhythmic account. Indeed, the present pattern of results points in the direction that other phonological (sublexical) properties may be playing a relevant role as well.

Although French belongs to the same rhythmic group as Spanish, Italian, and Greek, as can be seen from Table 2, it differs from them in many other dimensions. First, French has fixed final syllable stress - all its content words are stressed on the last syllable - and it has a relatively large number of vowels (14). In contrast, Spanish, Italian, and Greek are languages with variable stress-prominence can be given one of the last three syllables of content words - and they have a relatively small number of vowels (between 5 and 7). These two dimensions have proven to have important perceptual consequences. For instance, Dupoux et al. (1997) have shown that, contrary to Spanish listeners, French subjects have a lot of difficulties in making judgments on the basis of stress location. Also, Cutler and Norris (1988) have argued that the prototypical stress pattern in a language is used to segment the continuous speech into words. It is, then, possible that adjustments in lexical access routines that occur during the adaptation to compressed speech transfer better to languages that have similar suprasegmental properties. However, the results of both English and Japanese, two languages with variable stress/pitch accent, suggest that sharing this feature alone cannot account for the data. A second difference-namely, the vowel system-could also have an impact on the compression results. It is likely that speech compression at high rates distorts the phonetic realization of segments. It is, then, possible that adjustments at that phonetic level might transfer better to languages that share similar phoneme inventories. Although they used a different technique, Costa, Cutler, and Sebastián-Gallés (1998) reported speech-processing differences between Spanish and Dutch speakers, attributed to differences in the vowel/consonant ratio inventories in the two languages. However, this dimension would predict adaptation from Japanese to Spanish, two languages with five vowels.

More research is needed to tease apart these possibilities and to determine their specific weight in the adaptation mechanism. But our results already allow us to reject a simple explanation of all adaptation phenomena in terms of the simple three-class rhythmic hypothesis, and they suggest the relevance of phonological features, such as variable versus fixed stress and vowel repertoire. In order to account for the results, it seems necessary to consider a combination of more than one factor, among which language rhythm has to play a role.
Before closing, let us mention an unexpected finding that we discovered upon inspecting the detailed responses of the subjects. It was found that many subjects exposed to compressed Japanese and, to a lesser extent, to compressed English reported nonsense words in the very first experimental sentence (in Spanish). For example, the subjects in the Japanese adaptation group transcribed the test sentence "Le dije que volviera antes del mes de julio" ("I told him to come back before the month of July") with a series of nonsense words ("Legareis tot sugurus te tot"). Similarly, the subjects in the English induction group transcribed the same test sentences with strings of nonwords like "Leri a ye jurió." This type of answer was rare in the control and French groups and nonexistent in the Italian, Greek, and Spanish groups. To get a quantitative measure of this phenomenon, each first experimental sentence was classified according to whether it contained only nonsense syllables (the nonword category), contained some real Spanish words (the word category), or was impossible to classify (no response at all or only one function word, the other category).

As is shown in Table 3, the lexical/nonlexical nature of the responses to the first sentence after the language switch correlates well with adaptation. We performed a test of comparison of proportions ( $z$ scores) on the proportions of word responses and observed that (1) Spanish, Italian, Greek 50, and Greek30 did not differ from each other (all $z$ scores below 1.96, $p<.05$ or less); (2) Japanese was different from all the other adapting languages, except for English ( $p>.10$ or more), and (3) English and French did not differ from each other $(z=1.26$, n.s. $)$. Adapting languages (Italian and Greek), even if they are not understood by the subjects, induce them to report actual Spanish words in the compressed sentences. However, nonadapting languages (Japanese, English, and French) induce subjects to perceive their own language as foreign - that is, they do not report hearing words (Japanese inducing subjects to report fewer word category responses than does French). Remarkably, this pattern of results is not correlated with the lexical proximity of languages. Greek, a language lexically distant from Spanish, induces a lexical mode more than does, say, French, which is a lexically closer language. This corroborates our hypothesis that it is phonological information, not lexical information, that promotes adaptation to compressed speech. Phonologically close languages put the subjects into a maternal language processing mode, whereas phonolog-

Table 3

Percentage of Each Type of Responses in the First Two Experimental Sentences

\begin{tabular}{lrcc}
\hline Group & Word & Nonword & Other \\
\hline Control & 65 & 20 & 15 \\
Spanish & 90 & 0 & 10 \\
Italian & 100 & 0 & 0 \\
French & 60 & 10 & 30 \\
English & 40 & 35 & 25 \\
Japanese & 25 & 55 & 20 \\
Greek50 & 100 & 0 & 0 \\
Greek30 & 85 & 5 & 15 \\
\hline
\end{tabular}


ically more distant languages locally inhibit processing of the maternal language.

In conclusion, whatever the answer to these questions may turn out to be, we want to underline the usefulness of adaptation techniques for uncovering similarities and differences in the speech-processing systems. Discovering the exact nature of these adjustments may help uncover some of the essential aspects of language processing (see, e.g., Houde \& Jordan, 1998). These techniques have been able to show the contrasting processing of speakers of different languages by teasing apart lexical from phonological factors. Moreover, such a discovery may also help us find out why subjects have trouble with the perception of known foreign languages and with the perception of their native language when it is spoken with a foreign accent.

\section{REFERENCES}

AвERCRombie, D. (1967). Elements of general phonetics. Edinbugh: Edinburgh University Press.

Altmann, G. T. M., \& Young, D. (1993, September). Factors affecting adaptation to time-compressed speech. Paper presented at Eurospeech '93, Berlin.

Best, C. T., McRoberts, G. W., \& Sithole, N. N. (1988). The phonological basis of perceptual loss for non-native contrasts: Maintenance of discrimination among Zulu clicks by English-speaking adults and infants. Journal of Experimental Psychology: Human Perception \& Performance, 14, 345-360.

Charpentier, F. J., \& Stella, M. G. (1986, April). Diphone synthesis using an overlap-add technique for speech waveforms concatenation. Paper presented at the IEEE International Conference ASSP, Tokyo.

Costa, A., Cutler, A., \& Sebastián-Gallés, N. (1998). Effects of phoneme repertoire on phoneme decision. Perception \& Psychophysics, 60, 1022-1031.

Cutler, A., \& MeHLer, J. (1993). The periodicity bias. Journal of Phonetics, 21, 103-108.

Cutler, A., Mehler, J., Norris, D., \& Segui, J. (1983). A language specific comprehension strategy. Nature, 304, 159-160.

Cutler, A., Mehler, J., Norris, D., \& Seguí, J. (1989). Limits on bilingualism. Nature, 320, 229-230.

Cutler, A., \& Norris, D. G. (1988). The role of strong syllables in segmentation for lexical access. Journal of Experimental Psychology: Human Perception \& Performance, 14, 113-121.

DAUER, R. M. (1983). Stress-timing and syllable-timing reanalysed. Journal of Phonetics, 11, $51-62$.

Dupoux, E., Christophe, P., Sebastián, N., \& Mehler, J. (1997). A distressing deafness in French. Journal of Memory \& Language, 36, 406-421.

Dupoux, E., \& GreEN, K. (1997). Perceptual adjustment to highly compressed speech: Effects of talker and rate changes. Journal of Experimental Psychology: Human Perception \& Performance, 23, 914-927.

Finegan, E. (1987). English. In B. Comrie (Ed.), The world's major languages (pp. 77-109). London: Routledge.

Gото, H. (1971). Auditory perception by normal Japanese adults of the sounds "l" and "r." Neuropsychologia, 9, 317-323.

HOUDE, J. F., \& JoRDAN, M. I. (1998). Sensorimotor adaptation in speech production. Science, 279, 1213-1216.

ManN, V. A. (1986). Distinguishing universal and language-dependent levels of speech perception: Evidence from Japanese listeners' perception of English [1] and [r]. Cognition, 24, 169-196.

MCQueEn, J. M., Norris, D. G., \& Cutler, A. (1994). Competition in spoken word recognition: Spotting words in other words. Journal of Experimental Psychology: Learning, Memory, \& Cognition, 20, 621-638.

Mehler, J., Sebastián-Gallés, N., Altmann, G., Dupoux, E., Christophe, A., \& Pallier, P. (Eds.) (1993). Understanding compressed sentences: The role of rhythm and meaning. In P. Tallal, R. R.
Llinás, \& C. von Euler (Eds.), Temporal information processing in the nervous system: Special reference to dyslexia and dysphasia (Annals of the New York Academy of Sciences, Vol. 682, pp. 272-282). New York: New York Academy of Sciences.

Miyawaki, K., Strange, W., Verbrugge, R., Liberman, A. M., JenKINS, J. J., \& FuJimura, O. (1975). An effect of linguistic experience: The discrimination of $/ \mathbf{r} /$ and $/ \mathbf{l} /$ by native speakers of Japanese and English. Perception \& Psychophysics, 18, 331-340.

Norris, D. G., MCQueEn, J. M., \& Cutler, A. (1995). Competition and segmentation in spoken word recognition. Journal of Experimental Psychology: Learning, Memory, \& Cognition, 21, 1209-1228.

Otake, T., Hatano, G., Cutler, A., \& Mehler, J. (1993). Mora or syllable? Speech segmentation in Japanese. Journal of Memory \& Language, 32, 258-278.

Pallier, C., Bosch, L., \& Sebastián, N. (1997). A limit on behavioral plasticity in vowel acquisition. Cognition, 64, B9-B17.

Pallier, C., Sebastián, N., Felguera, T., Christophe, A., \& MEHLER, J. (1993). Attentional allocation within syllabic structure of spoken words. Journal of Memory \& Language, 32, 373-389.

Pallier, C., Sebastián-Gallés, N., Dupoux, E., Christophe, A., \& MeHLER, J. (1998). Perceptual adjustment to time-compressed speech: A cross-linguistic study. Memory \& Cognition, 26, 844-851

PIKE, K. L. (1946). The intonation of American English. Ann Arbor: University of Michigan Press.

Schwab, E. C., Nusbaum, H. C., \& Pisoni, D. B. (1985). Some effects of training on the perception of synthetic speech. Human Factors, 27, 395-408.

Sebastián-Gallés, N., Martí, A., Cuetos, F., \& Carreiras, M. (1996). LEXESP. Una base de datos informatizada del español [LEXESP: A computerized data-base of Spanish]. Barcelona: Universitat de Barcelona, Departamento de Psicologia Bàsica.

Sebastián-Gallés, N., \& Soto-Faraco, S. (1999). On-line processing of native and non-native phonemic contrasts in early bilinguals. Cognition, 72, 111-123.

Werker, J. F., \& Tees, R. C. (1984). Phonemic and phonetic factors in adult cross-language speech perception. Journal of the Acoustical Society of America, 75, 1866-1878.

\section{NOTE}

1. It has to be noted that the percentage of correct syllables for the Spanish induction group in the induction sentences is higher than the ones reported by Dupoux and Green (1997) for English. However, this percentage does not differ from some obtained by Mehler et al. (1993) and Pallier et al. (1998) for Spanish, Catalan, and French and from some reported by Altmann and Young (1993) for English. Therefore, although, in the present study, there are big differences in the understanding of the induction sentences across languages (mostly if we compare the understanding of compressed Spanish with the rest of the induction languages), it does not correlate with subjects' performance in the experimental sentences.

\section{APPENDIX Test Sentences}

- Le dije que volviera antes del mes de julio

(I told her to come back before July)

Cerró la puerta poco a poco, para no despertar a su hija

(She closed the door slowly so that she would not wake up her daughter)

- Esta silla es mucho más cómoda que la otra

(This chair is much more comfortable than the other one)

- Estas atletas han sido las ganadoras de la última carrera

(These athletes were the winners of the last race)

--Empezó a pintar hace tres meses

(She started to paint three months ago)

(Manuscript received January 20, 1998; revision accepted for publication April 26, 1999.) 